\title{
Do anaesthesiologists in pre-hospital care need concomitant clinical practice?
}

\author{
SJM Sollid ${ }^{1,2,3^{*}}$, M Sandberg $^{1,4}$, A Nakstad ${ }^{1}$, P Bredmose ${ }^{1}$ \\ From London Trauma Conference 2012 \\ London, UK. 4-7 December 2012
}

\section{Background}

Previous studies have documented that advanced life support (ALS) provided by anaesthesiologists in emergency medical service (EMS) leads to life years gained [1]. Especially interventions legally and formally related to anaesthesiology were judged as crucial: endotracheal intubation (ETI), chest tube insertion and anaesthesia induction. These interventions require extensive training and experience, and probably retraining and regular practice, to be performed safely. The need for retraining and practice is probably related to actual exposure to these interventions in clinical practice. To explore if there is a need for retraining and practice, we have investigated how often these interventions are performed by individual anaesthesiologists in a typical Norwegian physician manned EMS.

\section{Method}

Advanced interventions performed by the anaesthesiologist on call at three helicopter and car EMS units and one search-and-rescue unit were reported on a standard form for 12 months during 2011. Data on advanced airway management and surgical- and anaesthesiological procedures are reported here. Based on the number of prehospital working hours reported by each physician we calculated the number of procedures performed per 24-hour for each individual. With the mean value for each procedure per 24 hours per physician we have calculated the expected number of procedures performed in one year based on full time HEMS physician engagement equivalent to 84 24-hour shifts. The Data Protection Official of all involved institutions approved the data collection as a quality improvement project.

\section{Results}

We received forms from $82.7 \%$ of the 1460 duty-days covered by the study. Thirty-six individual physicians reported on their activities during the study and the mean number of duty hours per physician was 804.9 hours (IQR 273, 1315.5). The expected number of procedures performed per year per physician is listed in Table 1.

\section{Conclusion}

Anaesthesiologists in Norwegian EMS can expect relatively little exposure pre-hospital to crucial life-saving

Table 1 Expected number of procedures performed by the individual HEMS physician in full time HEMS engagement per year and expected time between each procedure exposure.

\begin{tabular}{lll}
\hline Procedure & n/year & Time between exposure \\
Paediatric ETI & 1.4 & 8.5 months \\
Adult ETI & 24.8 & 2 weeks \\
Surgical airway & 0.04 & 25 years \\
Chest tube insertion & 1.7 & 7 months \\
Anaesthesia induction & 19.6 & 2.5 weeks
\end{tabular}

${ }^{1}$ Air Ambulance Dept., Oslo University Hospital, Oslo, Norway

Full list of author information is available at the end of the article

(c) 2013 Sollid et al; licensee BioMed Central Ltd. This is an Open Access article distributed under the terms of the Creative Commons 
interventions. Concomitant in-hospital clinical practice and other skills retraining should therefore be maintained to ensure adequate proficiency in these interventions.

\section{Author details}

${ }^{1}$ Air Ambulance Dept., Oslo University Hospital, Oslo, Norway. ${ }^{2}$ Norwegian Air Ambulance Foundation, Norway. ${ }^{3}$ University of Stavanger, Stavanger, Norway. ${ }^{4}$ University of Oslo, Oslo, Norway.

Published: 28 May 2013

\section{Reference}

1. Lossius HM, Soreide E, Hapnes SA, Eielsen OV, Førde OH, Steen PA: Prehospital advanced life support provided by specially trained physicians: is there a benefit in terms of life years gained? Acta Anaesthesiol Scand 2002, 46:771-778.

doi:10.1186/1757-7241-21-S1-S7

Cite this article as: Sollid et al:: Do anaesthesiologists in pre-hospital care need concomitant clinical practice? Scandinavian Journal of Trauma, Resuscitation and Emergency Medicine 2013 21(Suppl 1):S7.

\section{Submit your next manuscript to BioMed Central} and take full advantage of:

- Convenient online submission

- Thorough peer review

- No space constraints or color figure charges

- Immediate publication on acceptance

- Inclusion in PubMed, CAS, Scopus and Google Scholar

- Research which is freely available for redistribution

Submit your manuscript at www.biomedcentral.com/submit 